\title{
Mechanism of Pulsus Paradoxus in Clinical Shock*
}

\author{
Jay N. Cohn, $\$$ Alan L. Pinkerson, and Felix E. Tristani \\ (From the Medical Service, Veterans Administration Hospital and the Department of Medicine, \\ Georgetozen University Medical Center, Washington, D. C.)
}

\begin{abstract}
An inspiratory fall in systolic arterial pressure of more than 10 $\mathrm{mm} \mathrm{Hg}$ (pulsus paradoxus) was noted in 30 of 61 patients with shock. Inspiratory right atrial pressures and total blood volumes were significantly lower in patients with pulsus paradoxus. Rapid infusion of dextran in 22 patients usually was effective in reversing the exaggerated inspiratory fall in systolic pressure. Total peripheral vascular resistance tended to be higher in the patients with pulsus paradoxus and administration of vasoconsrictor drugs often accentuated the respirator pressure variation.

Respiratory effects on blood flow in the aorta, pulmonary artery, and venae cavae were studied in anesthetized, closed-chest dogs. In the control state, pulmonary arterial flow increased during inspiration but aortic flow remained nearly constant. After hemorrhage a sharp inspiratory fall in aortic flow was associated with decreased central blood volume and attenuation of the usual inspiratory increase in venae caval and pulmonary arterial flows. The respiratory changes in aortic flow after hemorrhage could be attributed both to depletion of the pulmonary reservoir and to alterations in pulmonary inflow related to changes in systemic venous return.

These data indicate that blood volume depletion may precipitate pulsus paradoxus both in the anesthetized dog and in the critically ill patient. The occurrence of pulsus paradoxus may aid in the clinical recognition of the common syndrome of occult hypovolemia in patients with shock in the absence of signs of blood loss.
\end{abstract}

\section{Introduction}

An exaggerataed inspiratory fall in blood pressure is an important clinical finding in restrictive pericardial disease, and the mechanism of its occurrence in experimental pericardial effusion has been studied extensively (1-5). Pulsus paradoxus also has been observed in the presence of obstructive pulmonary disease associated with increased respiratory effort.

Pulsus paradoxus after hemorrhage was de-

* Received for publication 7 April 1967 and in revised form 12 July 1967.

This study was supported in part by U. S. Public Health Service Research grant HE-0978502 from the National Heart Institute.

¥ Address requests for reprints to Dr. Jay N. Cohn, V. A. Hospital, 50 Irving Street, N. W., Washington, D. C. 20422. scribed in a case report in 1903 (6) and its occurrence in patients with surgical shock was observed by Gauchat and Katz in 1924 (7). In our experience with direct arterial pressure recordings in patients with medical shock (8), an inspiratory fall in systolic arterial pressure greater than $10 \mathrm{~mm} \mathrm{Hg}$ was observed frequently in the absence of known causes of pulsus paradoxus.

The purpose of the present study was to elucidate the mechanism of pulsus paradoxus in clinical shock. The data reveal that a prominent fall in blood pressure often occurs during inspiration when blood volume is reduced and that volume expansion can correct this phenomenon. Experimental studies carried out in dogs confirmed that blood loss produces changes in flow which may lead to an exaggerated inspiratory fall in arterial pressure. 


\section{Methods}

Clinical studies. Studies were performed on patients who developed shock while in the medical wards of the Veterans Administration Hospital. The diagnosis of shock was based on the finding of an auscultatory systolic pressure of less than $90 \mathrm{~mm} \mathrm{Hg}$ associated with signs of inadequate peripheral blood flow, as manifested by cutaneous vasoconstriction, oliguria, or dulled sensorium. Patients were excluded from study if hemorrhage was felt to be an important factor contributing to the shock. If a vasopressor drug had been employed it was discontinued and the blood pressure was allowed to stabilize before hemodynamic studies were performed.

Studies were carried out at the bedside by a method previously described (8). The femoral artery was cannulated with a Teflon Longdwel needle or a radiopaque polyethylene catheter inserted by the Seldinger technique and advanced into the abdominal aorta. The right atrium was catheterized from the femoral vein with either a polyvinyl catheter advanced through a $14 \mathrm{G}$ thinwalled needle or a radiopaque catheter inserted by the Seldinger technique. Arterial and right atrial pressures were recorded with Statham $\mathrm{P} 23 \mathrm{Db}$ strain gage transducers and a Sanborn multichannel recorded. The zero reference level for pressures was the mid-thorax. Blood volume was determined with a calibrated injection of T-1824. Four or more blood samples were taken from 10 to $40 \mathrm{~min}$ after injection and the disappearance slope of T-1824 was extrapolated logarithmically back to the time of injection for calculation of plasma volume. Blood volume was calculated from the plasma volume by a method described previously (9). Normal values in this laboratory averaged $69.4 \pm 8$ (sD) $\mathrm{ml} / \mathrm{kg}$.

Cardiac output ( $\mathrm{CO}$ ) was measured in duplicate by the indicator dilution method. Indocyanine green dye was injected as a bolus into the right atrium while femoral arterial or aortic blood was drawn through a Gilford cuvette densitometer with a Gilford constant flow pump. Total peripheral vascular resistance was calculated from a standard formula (9). Low molecular weight dextran (dextran 40; Rheomacrodex) as a $10 \%$ solution in either saline or dextrose was infused intravenously under pressure, a $500 \mathrm{ml}$ infusion being completed within 15 or 20 min. Hemodynamic measurements were repeated immediately after completion of the infusion.

The records were analyzed of all patients with shock in whom hemodynamic studies were performed as described. Data were included for analysis if the heart rate was regular; the timing of respiration was clearly evident on the recording, and there were no findings to suggest restrictive pericardial disease.

Animal studies. Studies were performed on eight mongrel dogs (weight 10-20 kg) under anesthesia with pentobaribal $(25 \mathrm{mg} / \mathrm{kg})$ or morphine sulfate $(1-3 \mathrm{mg} / \mathrm{kg})$ and $10 \%$ chloralose in propylene glycol $(100 \mathrm{mg} / \mathrm{kg})$. Catheters were placed in the aorta and right atrium and pressures were recorded with Statham P23Db strain gages and a multichannel Sanborn recorder. Flow in the intrathoracic superior and inferior venae cavae (SVC and IVC) was measured with cannulating electromagnetic flow transducers (10). Flow in the ascending aorta and main pulmonary artery (PA) was measured with appropriately sized electromagnetic flow transducers placed around the vessels just distal to the semilunar valves. Flows were recorded simultaneously with a Statham M-4000, 400 cps multichannel flowmeter. Stroke volumes in the aorta and PA were calculated either by planimetry of flow curves recorded at 100 $\mathrm{mm} / \mathrm{sec}$ or by delivering the flow signal directly into an integrating amplifier. Respiratory cycles manifesting any sinus arrythmia were excluded from analysis.

After insertion of the flow probes the thoracotomy incision was closed and the lungs were reexpanded by completely evacuating air and blood from the pleural cavity. Since the pericardium was incised widely no pericardial fluid could accumulate. During the experiment, full lung expansion was assured by frequent attempts at pleural aspiration. Spontaneous respiration was established and respirations were recorded either with a balloon catheter in the pleural space or a pneumograph applied around the chest and connected to a low pressure Statham transducer.

Flow in the SVC, IVC, and aorta were recorded simultaneously in three animals and flow in the PA and aorta in the other five animals. Some animals were given an infusion of dextran to assure correction of possible hypovolemia before the hemorrhage procedure. The other animals were bled immediately after control flow and pressure measurements. Blood was removed from the aortic catheter in $50-\mathrm{ml}$ quantities with continuous monitoring of pressure and flow. After mean arterial pressure had been reduced to about $40 \mathrm{~mm} \mathrm{Hg}$ the shed blood was reinfused in three dogs.

In three dogs, central blood volume was measured in the control period and at frequent intervals during hemorrhage. Indocyanine green dye was injected as a bolus into the right atrium while blood was withdrawn from the ascending aorta through a Gilford cuvette densitometer using a Harvard pump. Cardiac output was calculated by standard techniques from the recorded dye curves and mean transit time was corrected for catheter and cuvette delay. Central blood volume was calculated as the product of the cardiac output and the mean transit time (9).

Statistical analyses were carried out using standard methods for calculating differences between means $(t)$ and correlation coefficients $(r)(11)$.

\section{Results}

Clinical studies. In 61 patients studied, the fall in systolic arterial pressure with inspiration (IFSP) ranged from 2 to $36 \mathrm{~mm} \mathrm{Hg}$ and averaged 11.4 $\mathrm{mm} \mathrm{Hg}$. Diastolic pressure fall ranged from 0 to $15 \mathrm{~mm} \mathrm{Hg}$ and averaged $5.9 \mathrm{~mm} \mathrm{Hg}$.

Significant correlations were noted between the respiratory fluctuations in right atrial pressure (RAP) and the IFSP $(r=0.454, P<0.01)$ and 


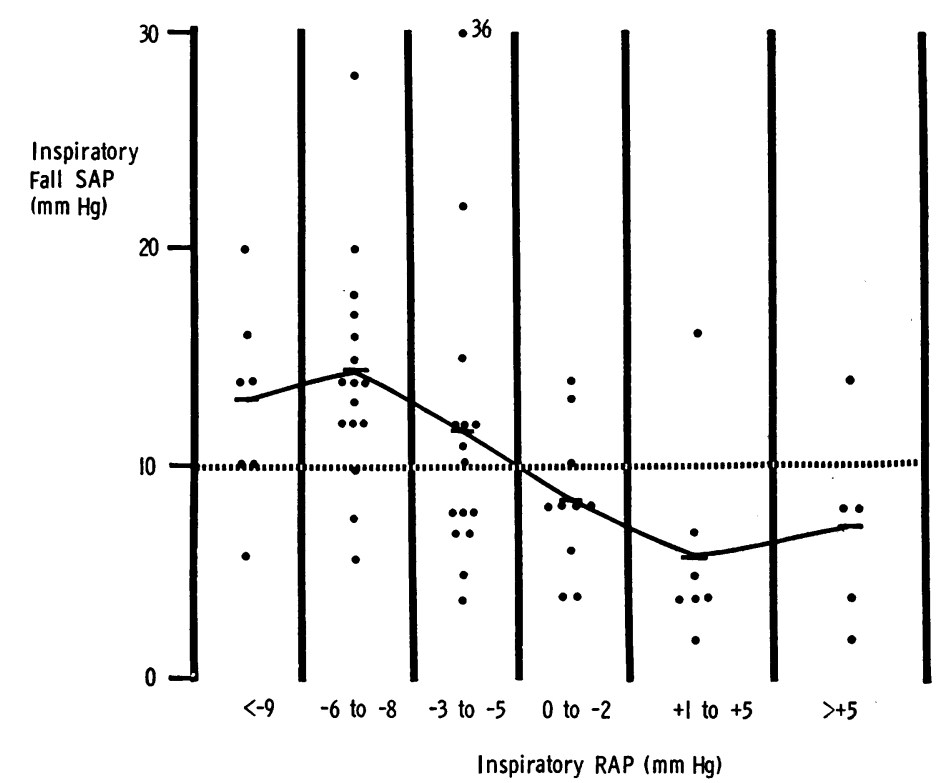

Fig. 1. INSPiratory fall in SYSTOLIC ARTERIAL PRESSURe (SAP) PLOTTED AGAINST GROUPED INSPIRATORY MEAN RIGHT ATRIAL PRESSURES $(R A P)$. Short horizontal marks connected by a line represent means of the different groups. Pulsus paradoxus (points above the broken line) is common with RAP less than $-3 \mathrm{~mm} \mathrm{Hg}$ but rare with higher inspiratory RAP.

between the inspiratory RAP and the IFSP $(r=$ $-0.327, P<0.01$ ) (Fig. 1). In 30 patients with IFSP of more than $10 \mathrm{~mm} \mathrm{Hg}$ (pulsus paradoxus), inspiratory RAP averaged $-4.9 \mathrm{~mm} \mathrm{Hg}$, compared to $-1.6 \mathrm{~mm} \mathrm{Hg}$ in the 31 patients without pulsus paradoxus $(P<0.02)$.

Blood volume was measured in 55 subjects and was inversely related to the IFSP $(r=-0.438$,

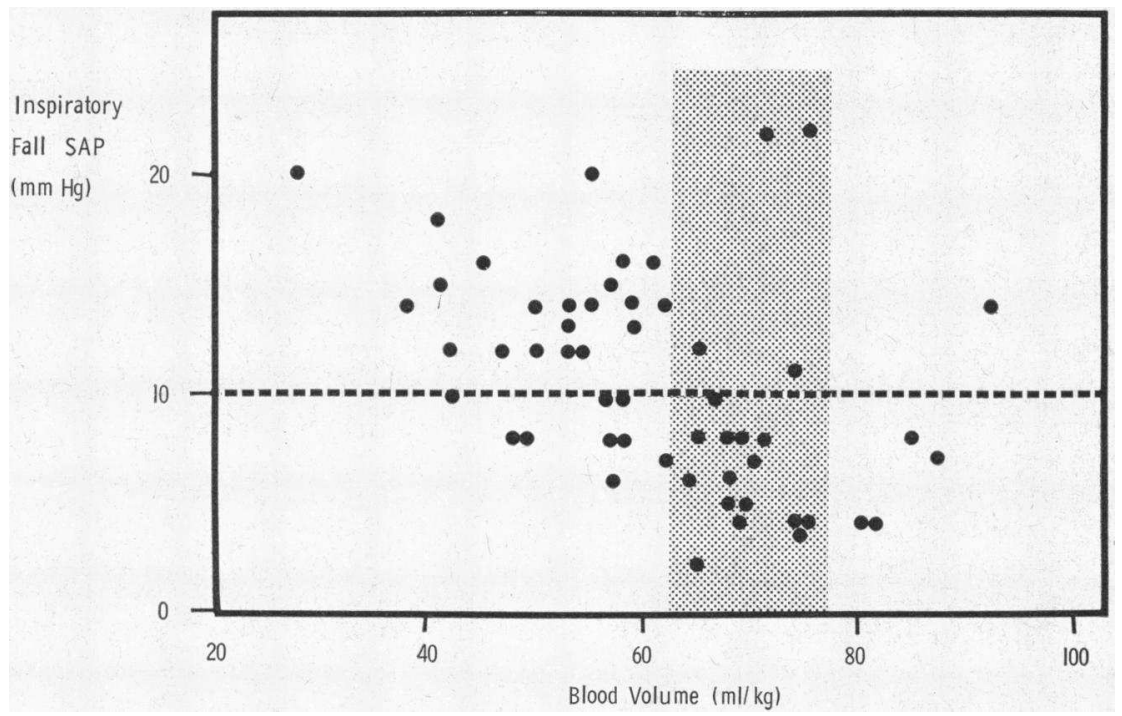

Fig. 2. INSPIRATORY FAll in SYSTOLIC ARTERIAL PRESSURE ( $S A P$ ) PLOTTEd AGAinst MEASURED TOTAL BLOOD VOLUME IN 55 PATIENTS WITH CLINICAL SHOCK. A significant correlation is demonstrated, $r=-0.438, P<0.01$. Dotted area represents normal blood volume \pm 1 sD. 

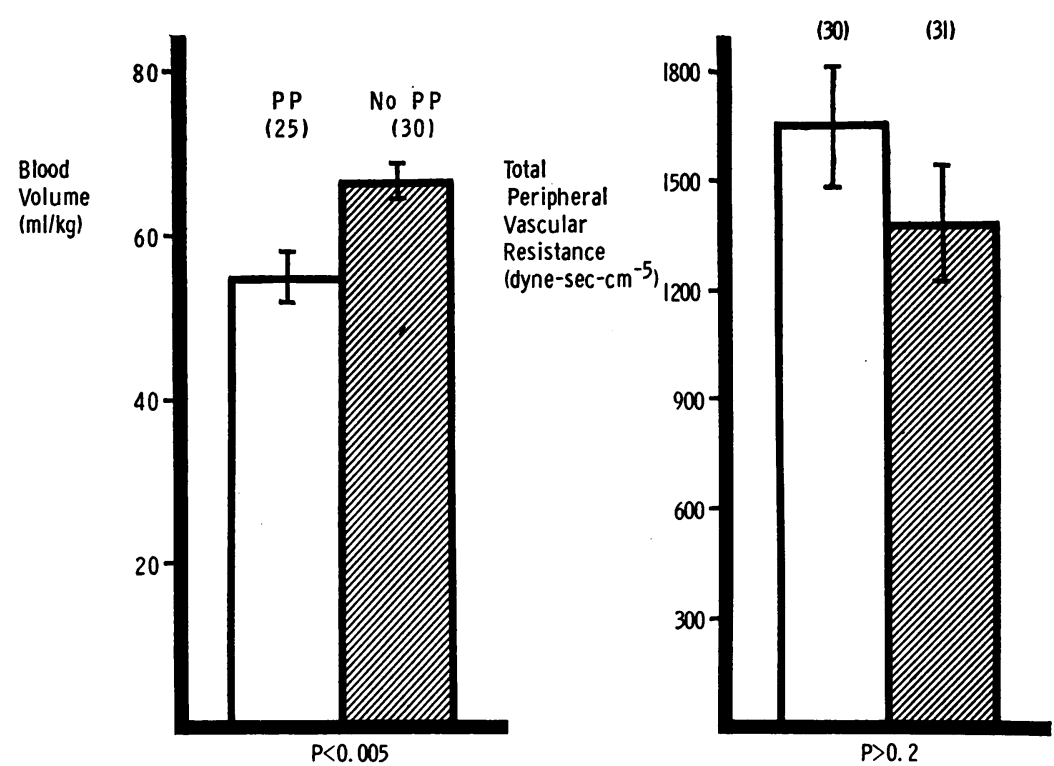

Fig. 3. Comparison between patients with $(P P)$ and without (no $P P$ ) PULSUS PARADOXUS (PP).

$P<0.01$ ) (Fig. 2). Blood volume averaged $55.5 \mathrm{ml} / \mathrm{kg}$ in patients with pulsus paradoxus and $66.4 \mathrm{ml} / \mathrm{kg}$ in those without $(P<0.005)$ (Fig. 3). All but five of the patients with pulsus paradoxus exhibited blood volumes of more than one standard deviation below the predicted normal value.

Pulsus paradoxus tended to occur in patients with low stroke volume (SV) and high total peripheral vascular resistance (PVR), but the correlation between IFSP and SV $(r=-0.345)$ and IFSP and PVR ( $r=0.252)$ was not as strong as that with blood volume. PVR averaged 1640 dyne-sec- $\mathrm{cm}^{-5}$ in patients with pulsus paradoxus and 1380 dyne-sec- $\mathrm{cm}^{-5}$ in those without. This difference was not statistically significant $(0.25>$ $P>0.2$ ) (Fig. 3). However, the rise in PVR which accompanied administration of a vasoconstrictor drug often was associated with accentuation of the IFSP (Fig. 4).

Rapid infusion of $500 \mathrm{ml}$ of low molecular weight dextran in patients with shock or hypotension expands blood volume, increases stroke volume, and decreases PVR (12). After administration of dextran, the IFSP was diminished in 21 of 22 patients with pulsus paradoxus (Figs. 5 and 6). The average respiratory variation in systolic pressure diminished from 15.6 to $9.3 \mathrm{~mm}$ $\mathrm{Hg}$. In 17 of the subjects dextran reduced the inspiratory fall to $10 \mathrm{~mm} \mathrm{Hg}$ or less. Respira- tory variation in diastolic pressure was not much altered by dextran, falling from an average of 7.5 to $5.7 \mathrm{~mm} \mathrm{Hg}$. After dextran the inspiratory RAP increased from an average of -0.6 to +4.3 $\mathrm{mm} \mathrm{Hg}$ while the respiratory fluctuation in RAP decreased from an average of 9.7 to $8.0 \mathrm{~mm} \mathrm{Hg}$.

Animal experiments. In the normovolemic or volume-expanded, closed-chest, anesthetized dog with spontaneous respirations, inspiration was associated with an increase in right ventricular stroke volume in all animals studied. Since heart
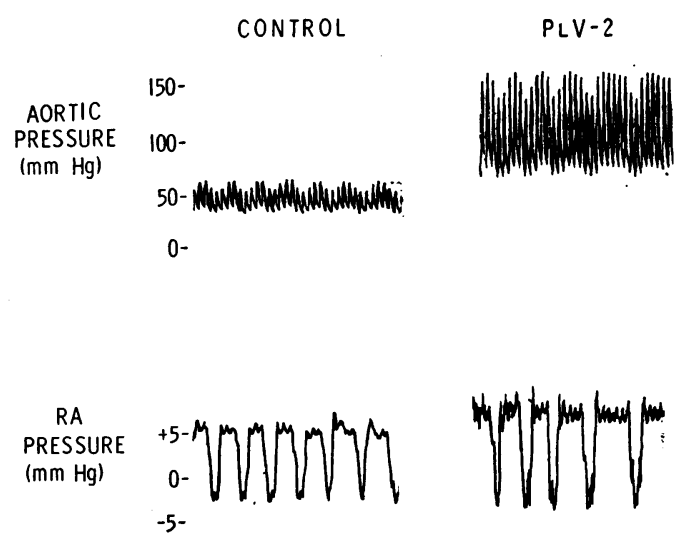

Fig. 4. EFFECT OF INFUSION OF THE VASOCONSTRICTOR AGENT OCTAPRESSIN (PLV-2) ON AORTIC PRESSURE AND RIGHT ATRIAL $(R A)$ PRESSURE IN A 75 YR OLD MAN WITH SEVERE HYPOTENSION. 
CONTROL

ECG

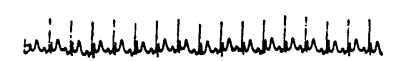

DEXTRAN

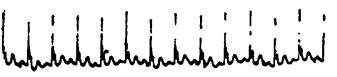

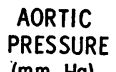
PRESSURE $(\mathrm{mm} ! \mathrm{Hg})$ $100-$ 50-

0 -

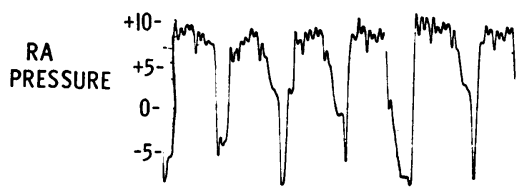

Fig. 5. EFFect of RAPID INFUSION of 500 ML OF DEXTRAN 40 IN A 58 YR OLD MAN WITH SEPTICEMIA. Right atrial $(R A)$ pressure is increased but respiratory fluctuations are only slightly reduced. Prominent pulsus paradoxus in control period disappears after dextran without any change in cardiac rhythm. rates were constant in all recordings analyzed, changes in stroke volume reflected similar changes in minute flow. PA flow usually increased dur-

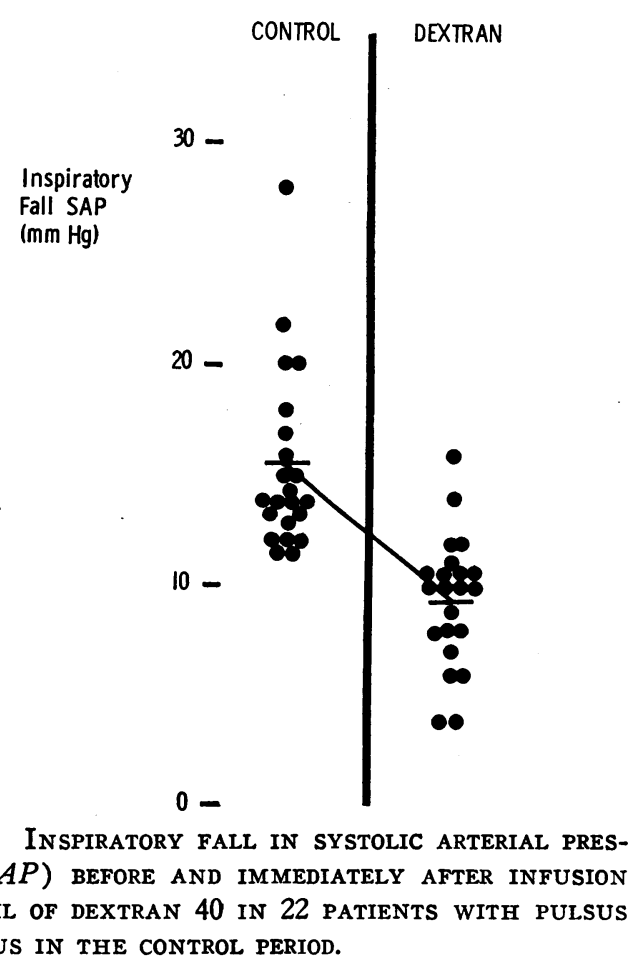
OF 500 ML OF DEXTRAN 40 IN 22 PATIENTS WITH PULSUS PARADOXUS IN THE CONTROL PERIOD. ing the first complete cardiac cycle after the onset of inspiration and returned to the expiratory level during the first complete cardiac cycle after the end of inspiration (Fig. 7). Aortic flow was only slightly altered by respiration, falling slightly during inspiration in seven dogs and remaining essentially unchanged in one. The slightly diminished inspiratory aortic stroke volume and the transmitted inspiratory negative intrathoracic pressure usually combined to produce a slightly lower arterial pressure during inspiration. (Figs. 7, 911).

Change in the volume contained between the PA and aortic flow probes was assessed by analyzing the relationship between simultaneous left and right ventricular stroke volumes. Right ventricular stroke volume usually surpassed left by an amount presumably equivalent to coronary flow. During inspiration the difference between PA and aortic flow always increased, indicating an increase in probe-to-probe volume, which includes the pulmonary vascular bed and the left heart.

After hemorrhage, large beat-to-beat fluctuations in aortic flow consistently appeared in all eight studies (Figs. 8-10). Most of these variations in flow could be related to the respiratory 
RESP.

(Insp.t)
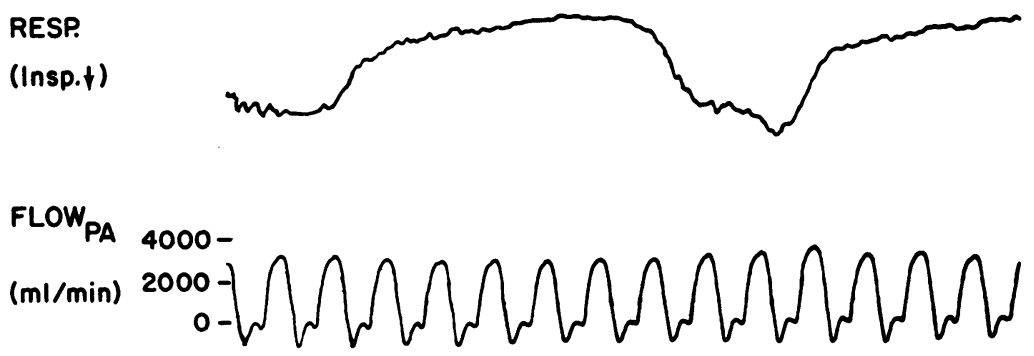

FLOW $_{\text {AO }}$

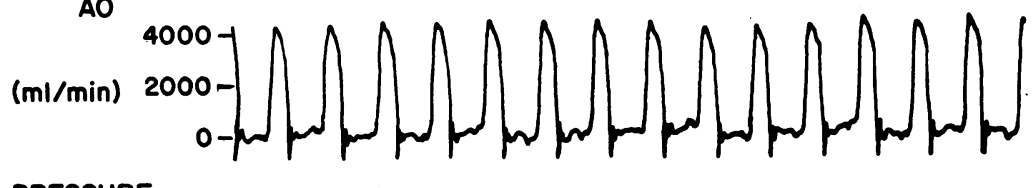

PRESSURE $_{A O}$

$(\mathrm{mm} \mathrm{Hg})$



Fig. 7. CONTROL RECORDING IN A CLOSED-CHEST DOG OF THE NORMAL RELATIONSHIP BETWEEN PULMONARY ARTERIAL FLOW $(P A)$, AORTIC FLOW $(A O)$, AND AORTIC PRESSURE $(A O)$. Inspiration augments PA flow and very slightly decreases aortic flow and pressure.

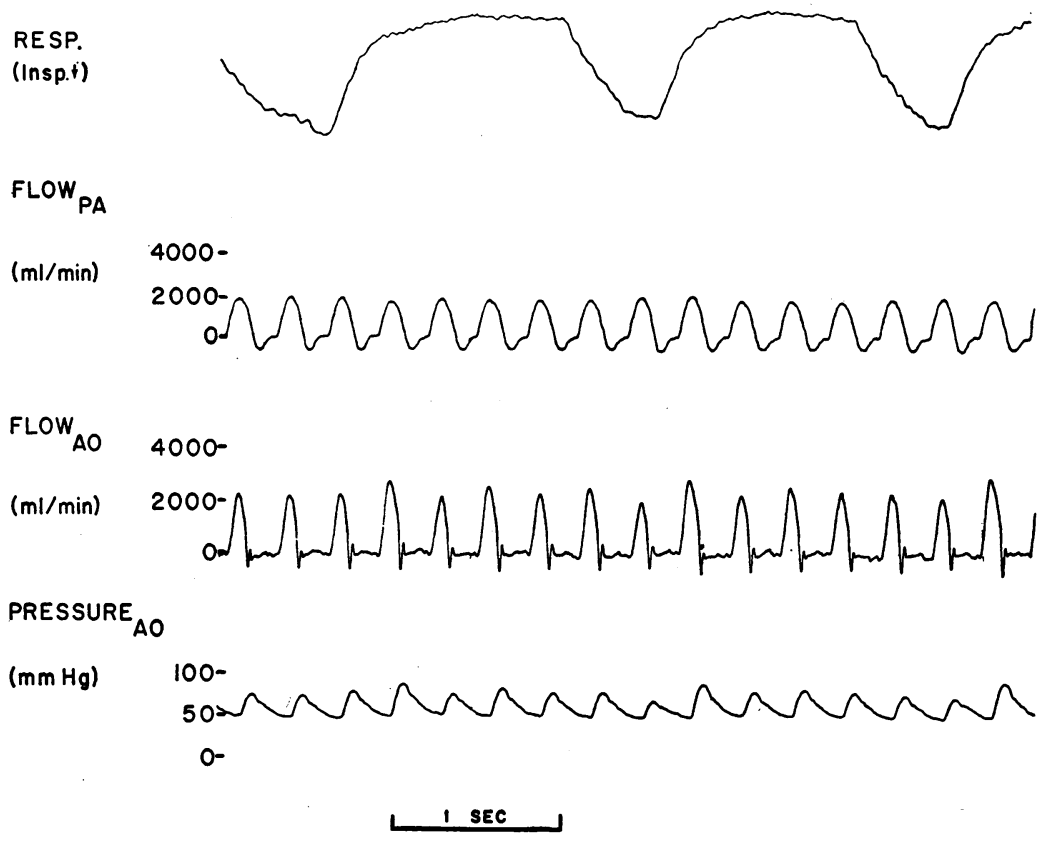

Fig. 8. SAME DOG AS SHOWN IN Fig. 7 AFTER HEMORRHAGE. Respiratory rate is more rapid but chest excursion is not altered. Inspiratory sugmentation of PA flow is attenuated. Aortic flow and pressure now fall sharply during inspiration and increase at the onset of expiration. 


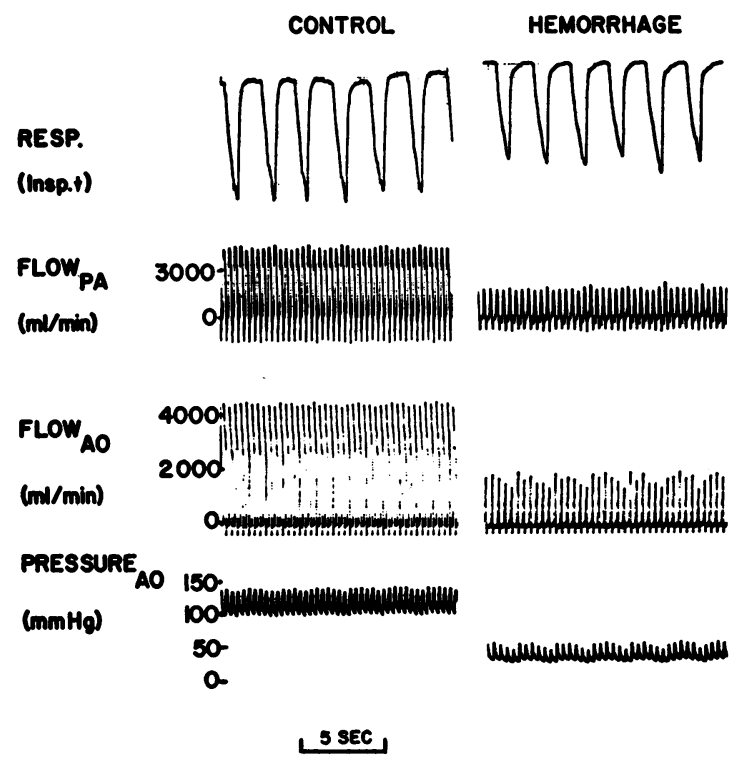

Fig. 9. Slow tracing Showing the flow Changes DURING RESPIRATION BEFORE AND AFTER HEMORRHAGE. Phasic changes in PA velocity and flow during the control period are attenuated after hemorrhage. On the contrary, aortic velocity and flow is nearly constant in the control period but fluctuates widely with respiration after hemorrhage. cycle. The largest left ventricular stroke volume and the highest arterial pressure always occurred during the first complete cardiac cycle after the onset of expiration, when blood was apparently mobilized from the pulmonary bed. Diminished left ventricular stroke volume was consistently observed during inspiration, the magnitude of the diminution in flow being related to the depth of the recorded inspiration and to the timing of respiration in relation to the cardiac cycle. When ventricular filling occurred just before the trough of negative intrathoracic pressure, the ensuing left ventricular stroke volume was markedly diminished (Figs. 8 and 9). The juxtaposition of a reduced left ventricular stroke volume near the end of inspiration followed by an augmented stroke volume at the beginning of expiration accentuated the respiratory alterations in aortic flow and pressure. The variations in aortic flow were completely reversed by reinfusion of the shed blood or by volume expansion with dextran.

The inspiratory increase in PA flow was attenuated in four of five animals after hemorrhage and disappeared completely in one study (Figs. 8-10).

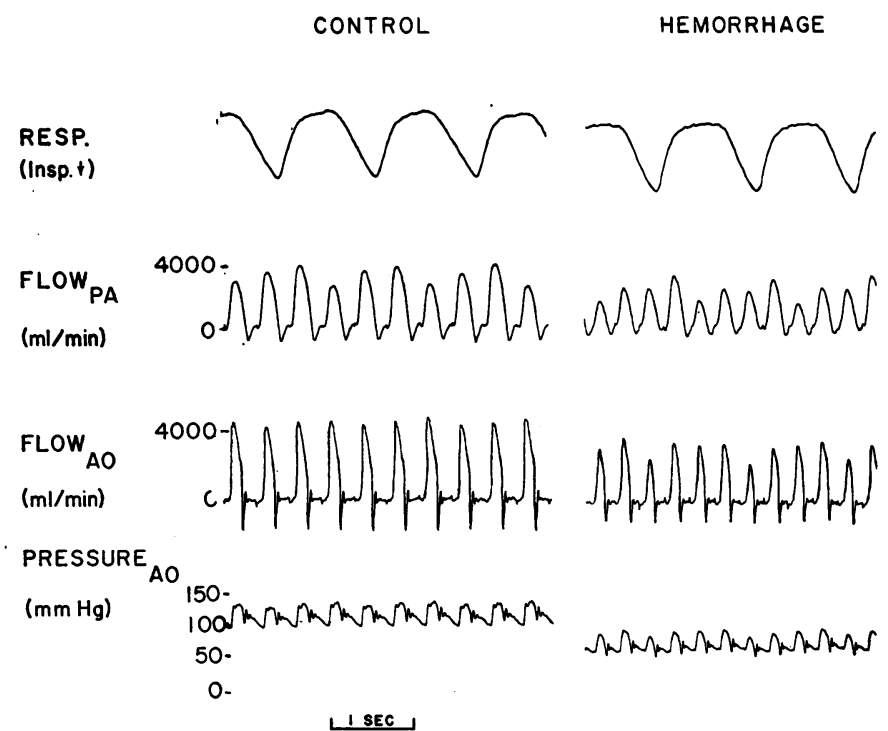

Fig. 10. Dog preparation IN Which PHASIC FluCtuations iN PA FLOW CONTINUE AFTER HEMORRHAGE DESPITE THE APPEARANCE OF A SHARP INSPIRATORY FALL IN AORTIC FLOW AND PRESSURE. After hemorrhage the inspiratory augmentation of PA flow is delayed, appearing after the onset of expiration in cycles in which the diastolic filling phase occurs late in inspiration. 
CONTROL
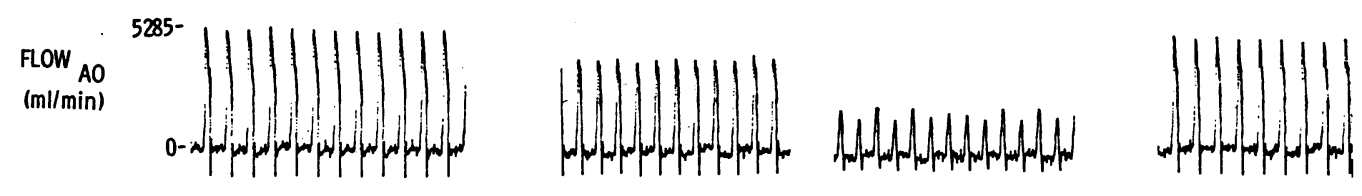

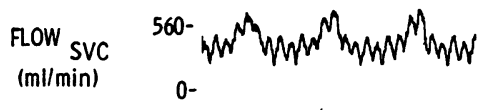

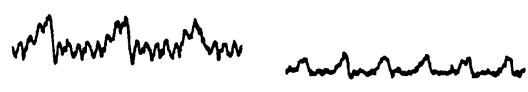

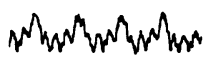
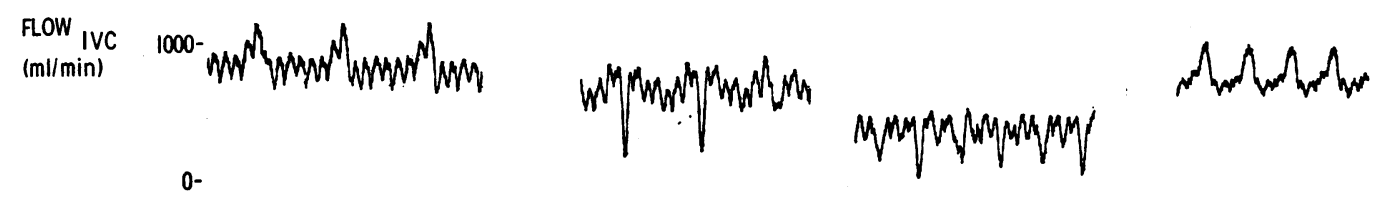

PRESSURE IP
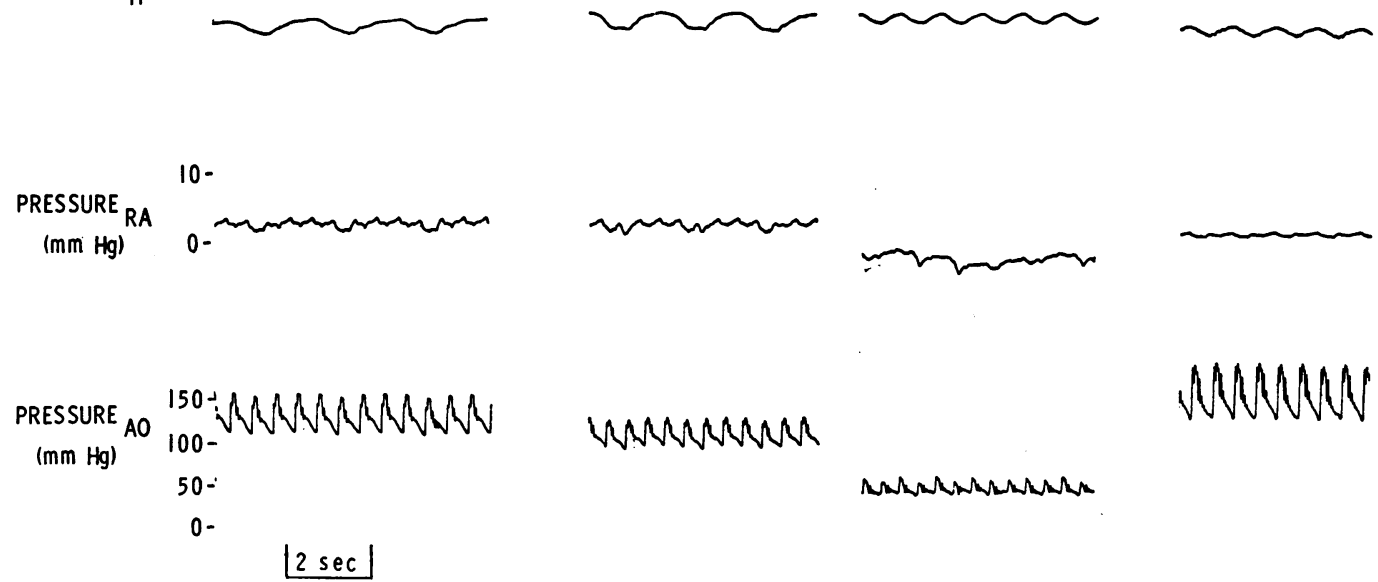

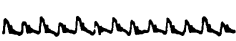

Fig. 11. RECORDiNg OF AORTIC $(A O)$, SUPERIOR VENA CAVAL (SVC), AND INFERIOR VENA CAVAL (IVC) FLOW IN A CLOSED-CHEST DOG. Intrapleural pressure $(I P)$ records respiratory activity (inspiration is downward deflection). In the control period SVC and IVC are augmented during inspiration and aortic flow and pressure are nearly constant. During hemorrhage, right atrial $(R A)$ and aortic $(A O)$ pressures fall. Respiratory fluctuations in AO flow occur concurrently with disappearance of the inspiratory augmentation of IVC flow and onset of a sharp, transient expiratory fall in caval flows. Small inspiratory increase in SVC flow persists, probably because flow is reduced nearly to zero during expiration. Reinfusion of the shed blood restores the control flow and pressure patterns, although tachypnea persists.

When augmentation of PA flow still occurred during inspiration it was usually delayed until the end of inspiration. Peak right ventricular stroke volume often appeared during the early expiratory phase when the diastolic filling period occurred during late inspiration (Fig. 10). During hypovolemia a sharp reduction in right ventricular stroke volume usually was observed during expiration. When expiration began during ventricular sys- tole, the next ventricular contraction generated a reduced right ventricular output and an increased left ventricular output. If expiration began during diastole, the increased left ventricular stroke volume still appeared on the next beat but the reduction in right ventricular stroke volume was delayed until the following beat.

IVC and SVC flows were measured before and after hemorrhage in three dogs. In the control 
studies caval blood flow was augmented simultaneously with the onset of inspiration and fell to the previous level at the beginning of expiration (Fig. 11). With progressive hemorrhage the inspiratory increase in flow diminished markedly in two of the studies. During hypovolemia the onset of expiration was consistently marked by a sharp, transient decrease in IVC flow. When respirations were properly timed, this event in the vena cava immediately preceded the expiratory fall in right ventricular stroke volume. These changes were reversed when the shed blood was reinfused (Fig. 11).

Central blood volume (CBV), which in this study included the heart and pulmonary bed, was measured in three studies. In the control period CBV averaged $211 \mathrm{ml}$. During hemorrhage CBV decreased progressively. At the time of appearance of marked respiratory variations in aortic flow, CBV was reduced by an average of $66 \mathrm{ml}$, or $31 \%$ of the initial CBV. Total blood loss at this time ranged from 200 to $450 \mathrm{ml}$.

\section{Discussion}

Although PA blood flow rises during normal inspiration, the concomitant increase in the capacity of the pulmonary vascular bed usually results in a slight decrease in left heart filling (1315). This hemodynamic effect of inspiration superimposed on the transmission of negative inspiratory intrathoracic pressure to the aorta usually produces a slight inspiratory fall in arterial pressure.

When systolic pressure falls more than $10 \mathrm{~mm}$ $\mathrm{Hg}$ with inspiration, the phenomenon is referred to as pulsus paradoxus. The mechanism of the exaggerated inspiratory fall in arterial pressure in pericardial tamponade has been extensively studied (1-5). Its occurrence in other situations has not received as much investigation. Indeed, pulsus paradoxus in shock unassociated with myocardial or pericardial disease has received only brief mention in the medical literature (7).

The occurrence of an inspiratory fall in systolic pressure of more than $10 \mathrm{~mm} \mathrm{Hg}$ in 30 of the 61 patients in this series seems clearly to have been related at least in part to hypovolemia, since the magnitude of the fall was statistically more closely related to reduced blood volume than to any other hemodynamic factor measured. The right atrial pressure during inspiration was lower in patients with pulsus paradoxus and the respiratory swings in atrial pressure were greater. Since intrathoracic pressure was not measured, the low inspiratory RAP could indicate either a fall in atrial transmural pressure due to limited venous return or accentuated excursions in intrathoracic pressure. The likelihood that an inadequate inspiratory augmentation of right atrial filling was at least partly responsible for the atrial pressure measurements is suggested by the observation that rapid volume expansion significantly increased the inspiratory RAP, slightly reduced the respiratory fluctuations in RAP, and corrected the pulsus paradoxus without producing any obvious immediate changes in the ventilatory effort.

The mechanism of the effect of hypovolemia on changes in blood flow and pressure with respiration was then studied in anesthetized dogs. When the animals had normal or expanded circulating volume, inspiration was associated with increased vena caval blood flow which was transmitted to the pulmonary artery during the next ventricular systole. This increased PA flow during inspiration apparently was retained within the expanded pulmonary vascular bed, since aortic flow usually decreased slightly during inspiration.

The maintenance of only slightly reduced pulmonary outflow despite enlargement of the pulmonary vascular bed during inspiration probably depends on at least two factors: $(a)$ an adequate reservoir of pulmonary blood, and $(b)$ augmented inflow during the early phase of inspiration. Because of the curvilinear pressure-volume relationship of the pulmonary vascular bed (16), an increment in pulmonary blood volume from a low initial volume will produce a smaller rise in transmural pressure than the same change in volume at a larger initial volume. When the pulmonary vessels are expanded, therefore, pulmonary venous transmural pressure may be maintained during inspiration by only a small increase in pulmonary blood volume. Indeed, left heart filling may remain adequate even if the inspiratory increase in pulmonary inflow is prevented (5). However, after depletion of the pulmonary blood reservoir, even a normal inspiratory increase in pulmonary volume may be inadequate to maintain the hydraulic gradient that determines left atrial filling. 
Since PA pulse waves are transmitted to the pulmonary veins of dogs with a delay of only 0.08$0.16 \mathrm{sec}(17)$, it is apparent that increased right ventricular stroke volume early in inspiration not only expands the pulmonary blood volume but may contribute directly to left ventricular filling during the ensuing diastolic interval. Therefore, during an inspiratory effort that encompasses two cardiac cycles, the volume of the second left ventricular ejection may be determined in part by the volume of the first right ventricular ejection. Thus, an augmentation of venous return and right ventricular output early in inspiration may help to maintain left ventricular filling later in inspiration, particularly when the pulmonary vascular bed is depleted and dependent on a considerable increase in volume to prevent an inspiratory fall in pulmonary venous transmural pressure.

The respiratory variations in aortic flow which were noted consistently after hemorrhage in the dog occurred when central blood volume was reduced an average of $31 \%$. Furthermore, the inspiratory increase in PA flow was attenuated and often delayed in appearance. Thus, both factors which could contribute to an inspiratory decrease in left ventricular filling were present. Another maneuver that depletes the pulmonary reservoir and prevents pulmonary inflow, namely temporary occlusion of the main pulmonary artery, has been shown by Hoffman and his associates also to result in a marked inspiratory fall in left ventricular stroke volume (15).

Studies of the patterns of vena caval flow revealed that attenuation of the inspiratory increase in right ventricular output after hemorrhage was related to reduction of the normal inspiratory increase in right atrial filling. This sequela of hemorrhage is probably related to a decreased volume in the large veins from which blood is usually mobilized during inspiration. In the hypovolemic animal a sharp, transient fall in caval flow was consistently observed at the onset of expiration. Positive intrathoracic pressure during the initiation of expiration may have exceeded the lowered extrathoracic venous pressure and reversed the usual hydraulic gradient favoring right atrial filling. This decrease in caval flow usually was manifest in the next cardiac cycle as a fall in right ventricular stroke volume. On some occasions this fall in pulmonary inflow was followed in the suc- ceeding cycle by a reduction in left ventricular stroke volume.

Most of the changes in right and left ventricular output after hemorrhage depend on the timing of respiration with respect to the cardiac cycle. Expiration immediately augments left ventricular output since blood mobilized from the lung flows promptly into the left atrium. However, the expiratory decrease in right atrial filling may not be manifest as a reduced right ventricular stroke volume until the next cardiac cycle if expiration begins during diastole, when the right heart may already contain blood which returned during the late phase of inspiration. Thus, although the characteristic effect of expiration in hypovolemia is to increase left ventricular stroke volume and to decrease right ventricular stroke volume, these phenomena may not be simultaneous.

Although aortic flow always fell during inspiration after hemorrhage, this effect was most prominent when inspiration was sufficiently prolonged to encompass two complete cardiac cycles. In this situation a sharp reduction in left ventricular output usually was observed during the second beat, perhaps in part because of an absence of the normal augmentation of right ventricular output during the first beat. When inspiration ended at the onset of diastole, early expiratory augmentation of left heart filling often prevented the occurrence of a significant fall in aortic flow. The pulsus paradoxus which develops after hemorrhage may therefore show considerable variation from one respiratory cycle to the next. The fluctuations in arterial pressure are clearly related to changes in aortic flow, and the apparent inspiratory fall in aortic pressure is as much dependent on augmented stroke volume during expiration as on reduced stroke volume during inspiration.

Several investigators have attributed respiratory changes in left ventricular output to phasic respiratory effects on right ventricular output which are delayed for several beats in their passage through the pulmonary bed (18-20). Shabetai and his associates reversed the pulsus paradoxus of pericardial tamponade by preventing an inspiratory increase in right heart filling (5), and the pulsus paradoxus observed during tilting and acceleration of normal subjects has been explained by Urschel as probably due to an exaggeration of the normal respiratory fluctuation in venous return to 
the right heart (20). Since passive tilting, acceleration, and hemorrhage all deplete central blood volume, it is likely that the mechanism of the pulsus paradoxus in these experimental situations is similar. The flow patterns recorded in the hypovolemic dogs in this study indicate that respiratory alterations in left ventricular output may occur independently from the right ventricle, since marked fluctuations in left ventricular stroke volume developed at a time when phasic variations in right ventricular stroke volume tended to disappear. Indeed, if the right ventricle played a role in the fluctuations in aortic flow in this situation it was because of an attenuation of the usual increase in right heart filling and output during inspiration. Although no conclusions can be reached from this study regarding the mechanism of pulsus paradoxus in other clinical and experimental situations, it is clear that circulating blood volume depletion results in an exaggerated decrease in left ventricular filling during inspiration.

Other factors may contribute to pulsus paradoxus in patients in shock. Increased inspiratory effort or ventilatory obstruction accentuate the negative intrapleural pressure that is transmitted to the aorta. However, the effect of transmitted intrathoracic pressure should be observed in both the systolic and diastolic aortic pressure (14), whereas changes in stroke volume would primarily alter the systolic pressure. The observations that systolic pressure fell considerably more than diastolic pressure in the volume-depleted patients, and that volume expansion had its greatest effect on the systolic pressure change with respiration suggest that flow changes were more important in the observed responses.

An exaggerated increase in the pulmonary vascular capacity as a result of increased inspiratory effort also could impair left heart filling during inspiration. While stertorous breathing was common in these patients, volume expansion usually corrected the pulsus paradoxus with no apparent change in the respiratory effort and only a slight decrease in the respiratory fluctuations in the right atrial pressure. Furthermore, the inspiratory fall in left ventricular output after hemorrhage in the dogs was not necessarily associated with any change in the excursions of the chest or in the magnitude of fluctuations of intrapleural pressure.
Generalized systemic vasoconstriction would tend to magnify the pressure effects of small changes in aortic flow, since the pressure change resulting from a given change in flow is directly proportional to the PVR. Indeed, administration of vasoconstrictor drugs often accentuated the inspiratory fall in systolic pressure. The PVR tended to be higher in patients with pulsus paradoxus, but elevated PVR and hypovolemia are closely related in shock (21) and the correlation between PVR and pulsus paradoxus might therefore be fortuitous.

The observation of reduced blood volume in many of these patients, none of whom had sustained a significant hemorrhage, indicates that occult volume depletion may occur frequently in shock. Since rapid volume expansion usually produces striking improvement in these patients (12), prompt recognition of hypovolemia may be of great clinical importance. While pulsus paradoxus remains a clinical phenomenon of multiple cause, its presence in a patient with severe hypotension or shock in the absence of venous engorgement should be accepted as presumptive evidence of blood volume depletion.

\section{References}

1. Katz, L. N., and H. W. Gauchat. 1924. Observations on pulsus paradoxus (with special reference to pericardial effusion). II. Experimental. Arch. Internal Med. 33: 371.

2. Dornhorst, A. C., P. Howard, and G. L. Leathart. 1952. Pulsus paradoxus. Lancet. 1: 746.

3. Sharp, J. T., I. L. Bunnell, J. F. Holland, G. T. Griffith, and D. G. Greene. 1960. Hemodynamics during induced cardiac tamponade in man. $A m . J$. Med. $29: 640$.

4. Golinko, R. J., N. Kaplan, and A. M. Rudolph. 1963. The mechanism of pulsus paradoxus during acute pericardial tamponade. J. Clin. Invest. 42: 249.

5. Shabetai, R., N. O. Fowler, J. C. Fenton, and M. Masangkay. 1965. Pulsus paradoxus. J. Clin. Invest. $44: 1882$.

6. Riegel, F. 1903. Ueber Pulsus paradoxus. Deut. Med. Wochschr. $29: 345$.

7. Gauchat, H. W., and L. N. Katz. 1924. Observations on pulsus paradoxus (with special reference to pericardial effusions). I. Clinical. Arch. Internal Med. 33 : 350.

8. Cohn, J. N., and M. H. Luria. 1964. Studies in clinical shock and hypotension. The value of bedside hemodynamic observations. J. Am. Med. Assoc. $190: 891$. 
9. Cohn, J. N., and M. H. Luria. 1965. Studies in clinical shock and hypotension. II. Hemodynamic effects of norepinephrine and angiotensin. J. Clin. Invest. 44 : 1494.

10. Pinkerson, A. L., M. H. Luria, and E. D. Freis. 1966. Effect of cardiac rhythm on vena caval blood flows. Am. J. Physiol. 210: 505.

11. Hill, A. B. 1961. Principles of Medical Statistics. Oxford University Press, New York. 7th edition.

12. Cohn, J. N., M. H. Luria, R. C. Daddario, and F. E. Tristani. 1967. Studies in clinical shock and hypotension. V. Hemodynamic effects of dextran. Circulation. 35 : 316.

13. Coleridge, J. C. G., and R. J. Linden. 1959. The variations with respiration in effective right and left atrial pressures in the dog. J. Physiol., (London). 145: 482.

14. Shabetai, R., N. O. Fowler, and M. Gueron. 1963. The effect of respiration on aortic pressure and flow. Am. Heart J. 65 : 525.

15. Hoffman, J. I. E., A. Guz, A. A. Charlier, and D. E. L. Wilcken. 1965. Stroke volume in conscious dogs; effect of respiration, posture and vascular occlusion. J. Appl. Physiol. $20: 865$.

16. Fishman, A. P. 1963. Dynamics of the pulmonary circulation. In Handbook of Physiology: Circulation. W. F. Hamilton, editor. American Physiological Society, Washington, D. C. 2 : 1667.

17. Pinkerson, A. L. 1967. Pulse wave propogation through the pulmonary vascular bed of dogs. $\mathrm{Am}$. J. Physiol. 213 : 450.

18. Dornhorst, A. C., P. Howard, and G. L. Leathart. 1952. Respiratory variations in blood pressure. Circulation. 6: 553.

19. Lange, R. L., and T. J. Tsagaris. 1964. Time course of factors causing exaggerated respiratory variation of arterial blood pressure. J. Lab. Clin. Med. $63: 431$.

20. Urschel, C. W. 1967. Pulsus paradoxus. Effect of gravity and acceleration in its production. $\mathrm{Am}$. J. Cardiol. $19: 360$.

21. Cohn, J. N., and M. H. Luria. 1966. Studies in clinical shock and hypotension IV. Variations in reflex vasoconstriction and cardiac stimulation. Circulation. $34: 823$. 